\title{
MADURACIÓN Y GERMINACIÓN DE EMBRIONES SOMÁTICOS DE Coffea arabica CV. COLOMBIA
}

\section{MATURATION AND GERMINATION OF SOMATIC EMBRYOS OF Coffea arabica CV. COLOMBIA}

\author{
Enrique Riviello-Cogco ${ }^{1}$, Alejandrina Robledo-Paz ${ }^{1 *}$, María A. Gutiérrez- \\ Espinosa ${ }^{1}$, Javier Suárez-Espinosa ${ }^{2}$ y José Oscar Mascorro-Gallardo ${ }^{3}$
}

\begin{abstract}
${ }^{1}$ Colegio de Postgraduados (CP), Campus Montecillo, Posgrado en Recursos Genéticos y Productividad, Montecillo, Texcoco, Estado de México, México. ${ }^{2} \mathrm{CP}$, Campus Montecillo, Posgrado en Socioeconomía, Estadística e Informática, Montecillo, Texcoco, Estado de México, México. ${ }^{3} U n i v e r s i d a d$ Autónoma Chapingo, Departamento de Fitotecnia, Chapingo, Texcoco, Estado de México, México.
\end{abstract}

*Autor de correspondencia (arobledo@colpos.mx)

\section{RESUMEN}

La variedad de café Colombia (Coffea arabica L.) tiene alta resistencia a la roya y buenas características de producción y calidad de taza. Diversos protocolos para la propagación de café mediante embriogénesis somática han sido desarrollados; sin embargo, la tasa de maduración, germinación y conversión es baja. El objetivo de la presente investigación fue determinar el efecto de reguladores del crecimiento y agentes osmóticos en la maduración y germinación de embriones somáticos de café y evaluar, en condiciones ex vitro, las características fisiológicas de las plantas regeneradas. Para su maduración, embriones globulares y torpedo temprano se cultivaron en un medio Yasuda et al. (1985) con distintas concentraciones de ácido abscísico (ABA) (2-4 mg L $\left.\mathrm{L}^{-1}\right)$, ácido salicílico (ASA) $\left(1.38 \mathrm{~g} \mathrm{~L}^{-1}\right)$, ácido giberélico $\left(\mathrm{AG}_{3}\right)$ (0.7-1.0 mg L-1), ácido indolacético (AIA) $\left(0.3-0.5 \mathrm{mg} \mathrm{L}^{-1}\right)$, polietilenglicol 8000 (PEG 8000) (50-75 g L-1) o sacarosa $\left(50-80 \mathrm{~g} \mathrm{~L}^{-1}\right)$. Para su germinación, los embriones maduros fueron transferidos a un medio con $0.25 \mathrm{mg} \mathrm{L}^{-1} \mathrm{de}$ AIA y $0.25 \mathrm{mg} \mathrm{L}^{-1}$ de 6-bencilaminopurina (BAP). Las plantas se aclimataron y crecieron en perlita:turba:tezontle (1:1:1) o turba:tezontle (2:1) en condiciones de invernadero. El valor máximo de maduración y germinación de los embriones globulares se observó al adicionar $50 \mathrm{~g} \mathrm{~L}^{-1}$ de sacarosa al medio (81.7 y $53.9 \%$, respectivamente). Para los embriones torpedo temprano el porcentaje de maduración más alto se registró con $80 \mathrm{~g} \mathrm{~L}^{-1}$ de sacarosa $(19.2$ \%) o una combinación de $1.0 \mathrm{mg} \mathrm{L}^{-1}$ de $\mathrm{AG}_{3}$ y $0.5 \mathrm{mg} \mathrm{L}^{-1}$ de AIA (45.0\%); sin embargo, los porcentajes de germinación no fueron significativamente distintos del testigo. El potencial osmótico de los embriones no estuvo directamente relacionado con su grado de madurez. La totalidad de las plantas cultivadas en las mezclas de sustratos sobrevivieron y mostraron ser morfológica y fisiológicamente normales bajo condiciones ex vitro.

Palabras clave: Coffea arabica, embriogénesis somática, germinación, maduración, osmóticos, reguladores de crecimiento.

\section{SUMMARY}

The Colombia coffee variety (Coffea arabica L.) has high resistance to rust and good production characteristics and cup quality. Several protocols have been developed for the propagation of coffee by somatic embryogenesis; however, the rate of maturation, germination and conversion is low. The objective of this study was to determine the effect of growth regulators and osmotic agents on the maturation and germination of coffee somatic embryos and to evaluate, under ex vitro conditions, the physiological characteristics of the regenerated plants. For maturation, globular and early torpedo embryos were cultured on a Yasuda et al. (1985) medium with different concentrations of abscisic acid (ABA) (2-4 $\left.\mathrm{mg} \mathrm{L}^{-1}\right)$, salicylic acid (SA) (1.38 $\left.\mathrm{g} \mathrm{L}^{-1}\right)$, gibberellic acid $\left(\mathrm{GA}_{3}\right)\left(0.7-1.0 \mathrm{mg} \mathrm{L}^{-1}\right)$, indoleacetic acid (IAA) $(0.3-0.5$ $\left.\mathrm{mg} \mathrm{L}^{-1}\right)$, polyethylene glycol 8000 (PEG 8000$)\left(50-75 \mathrm{~g} \mathrm{~L}^{-1}\right)$ or sucrose $(50-80$ $\left.\mathrm{g} \mathrm{L}^{-1}\right)$. For germination, the mature embryos were transferred into a medium with $0.25 \mathrm{mg} \mathrm{L}^{-1}$ of IAA and $0.25 \mathrm{mg} \mathrm{L}^{-1}$ of 6 -benzylaminopurine (BAP). The plants were acclimatized and grown on perlite:peat:volcanic rock (1:1:1) or peat:volcanic rock $(2: 1)$ under greenhouse conditions. The maximum value of maturation and germination of globular embryos was observed when $50 \mathrm{~g}$ $\mathrm{L}^{-1}$ of sucrose were added to the medium ( 81.7 and $53.9 \%$, respectively). For early torpedo embryos, the highest percentage of maturation was recorded with $80 \mathrm{~g} \mathrm{~L}^{-1}$ of sucrose $(19.2 \%)$ or a combination of $1.0 \mathrm{mg} \mathrm{L}^{-1} \mathrm{GA}_{3}$ and $0.5 \mathrm{mg} \mathrm{L}^{-1}$ of IAA ( $45.0 \%$ ); however, the germination percentages were not significantly different from the control. The osmotic potential of the embryos was not directly related to their degree of maturity. All the plants grown on the substrate mixtures survived and were morphologically and physiologically normal under ex vitro conditions.

Index words: Coffea arabica, germination, growth regulators, maturation, osmotic, somatic embryogenesis.

\section{INTRODUCCIÓN}

El café (Coffea arabica L.) es un cultivo estratégico para México, ya que genera más de tres millones de empleos y representa $0.66 \%$ del PIB agrícola nacional (SAGARPA, 2017). La superficie cultivada con este grano es de aproximadamente 680,120 hectáreas, siendo Chiapas (35.5\%), Veracruz (21.2\%), Oaxaca (17.8\%) y Puebla (10.2\%) los principales estados productores (SIAP, 2020). En los últimos años, la producción de café en México ha reportado su nivel mínimo desde que se tiene registro, debido a factores como la avanzada edad de las plantaciones, afectaciones climatológicas, mala nutrición y la roya del café causada por el hongo Hemileia vastatrix Berk. y Br., que durante el ciclo productivo 2012-2013 afectó severamente las zonas cafetaleras de los estados de Chiapas, Puebla y Veracruz (Renard y Larroa, 2017; USDA, 2018).

Hasta 2013, las variedades de café no resistentes a la 
roya del cafeto (Typica, Bourbon y Caturra Rojo) tenían una marcada dominancia en México, situación que llevó al uso constante de fungicidas para controlar esta enfermedad, lo que no sólo tuvo un efecto negativo en el costo de producción sino también en el ambiente (Renard y Larroa, 2017), es por ello que el gobierno mexicano implementó programas para aumentar la productividad del sector cafetalero creando viveros certificados para suministrar a los productores plantas de calidad resistentes a dicha enfermedad. La meta es renovar 250 mil hectáreas, para lo cual se requerirán 750 millones de plantas (USDA, 2018).

La renovación de plantaciones con materiales resistentes a la roya como la variedad Colombia es parte de la estrategia para reducir los efectos de esta enfermedad (USDA, 2018); no obstante, la tasa de reproducción de los sistemas tradicionales de propagación mediante semillas o esquejes no permite cubrir la demanda de plantas que se tiene para llevar a cabo dicha renovación (Kumar et al., 2006).

El cultivo de tejidos mediante la embriogénesis somática ha permitido la propagación a gran escala de distintas especies vegetales (Campos et al., 2017). Diversos protocolos para la propagación de café han sido desarrollados mediante embriogénesis somática (Aga y Khillare, 2017; Etienne et al. 2013; 2018; Georget et al., 2017; Kahia et al., 2016; Montes-Cruz et al., 2017); no obstante, la baja tasa de maduración, germinación y conversión de los embriones en plantas son algunos de los factores que limitan su aplicación en los programas de producción y mejoramiento de café (Rezende et al., 2011).

Si bien existen numerosos trabajos sobre embriogénesis somática en el género Coffea, pocos se han centrado en mejorar la maduración de los embriones. Reguladores de crecimiento y osmóticos han sido utilizados para promover la maduración de los embriones somáticos de café y otras especies. Al respecto, Pereira et al. (2007) reportaron incremento en el porcentaje de maduración de embriones somáticos de $C$. arabica var. Acaiá cuando adicionaron ácido giberélico $\left(\mathrm{AG}_{3}\right)$ al medio de cultivo, en tanto que en $C$. canephora var. Robusta, hubo mejora en la maduración de los embriones en presencia de ácido abscísico (ABA) o una combinación de bencilaminopurina (BAP) y sacarosa (Etienne, 2005; González et al., 2000). Altas concentraciones de sacarosa en el medio (50 a $90 \mathrm{~g} \mathrm{~L}^{-1}$ ) también incrementaron la tasa de maduración de embriones somáticos de Juglans regia y Picea abies (Businge et al., 2013; Hazubska-Przybyl et al., 2016; Vahdati et al., 2008); asimismo, la adición de agentes osmóticos como polietilenglicol (PEG) al medio de cultivo mejoró la maduración de embriones somáticos de Leucojum aestivum, P. abies y Carica papaya (Businge et al., 2013; Ptak et al., 2013; Vale et al., 2014). Por lo anterior, el objetivo de la presente investigación fue determinar el efecto de reguladores del crecimiento y agentes osmóticos en la maduración y germinación de embriones somáticos de café var. Colombia y evaluar en condiciones ex vitro las características fisiológicas de las plantas regeneradas.

\section{MATERIALES Y MÉTODOS}

\section{Inducción de la embriogénesis somática}

La inducción y diferenciación de embriones somáticos se llevó a cabo siguiendo el protocolo reportado por Avila-Victor et al. (2018). Segmentos de $1 \mathrm{~cm}^{2}$ de hojas previamente desinfestadas se cultivaron durante dos meses en un medio que contenía las sales del medio de Murashige y Skoog (1962) (MS), $0.5 \mathrm{mg} \mathrm{L}^{-1}$ de ácido 2,4-diclorofenoxiacético (2,4-D), $1.1 \mathrm{mg} \mathrm{L}^{-1}$ de BAP, $100 \mathrm{mg}$ $\mathrm{L}^{-1}$ de ácido cítrico, $200 \mathrm{mg} \mathrm{L}^{-1}$ de ácido ascórbico, $30 \mathrm{~g} \mathrm{~L}^{-1}$ de sacarosa y $5.2 \mathrm{~g} \mathrm{~L}^{-1}$ de Phytagel. Los callos generados se transfirieron a un medio elaborado con las sales del medio reportado por Yasuda et al. (1985) modificadas, 1.1 $\mathrm{mg} \mathrm{L}^{-1}$ de BAP y $30 \mathrm{~g} \mathrm{~L}^{-1}$ de sacarosa. El pH de los medios se ajustó a 5.7 o 6.3 y fueron esterilizados durante 15 min en autoclave a $121{ }^{\circ} \mathrm{C}$. Luego de cuatro meses, los embriones en etapa globular y torpedo temprano fueron colectados para su maduración (Figura 1 A).

\section{Maduración de los embriones somáticos}

Los embriones somáticos en etapa globular se cultivaron durante 40 días en cajas Petri de $60 \times 15 \mathrm{~mm}$ que contenían $15 \mathrm{~mL}$ de medio formulado con las sales de Yasuda et al. (1985) modificadas, $0.2 \mathrm{mg} \mathrm{L}^{-1}$ de BAP, 0.2 $\mathrm{mg} \mathrm{L}^{-1}$ de ácido indolacético (AIA), $30 \mathrm{~g} \mathrm{~L}^{-1}$ de sacarosa, 2.3 $\mathrm{g} \mathrm{L}^{-1}$ de Phytagel, además de ácido abscísico (ABA) (2, 3 y $4 \mathrm{mg} \mathrm{L}^{-1}$ ), polientilenglicol 8000 (PEG 8000) (50 y $75 \mathrm{~g} \mathrm{~L}^{-1}$ ), $1.38 \mathrm{~g} \mathrm{~L}^{-1}$ de ácido salicílico (ASA) o sacarosa $(30,50,60 \mathrm{y}$ $80 \mathrm{~g} \mathrm{~L}^{-1}$ ) (Figura $1 \mathrm{~B}$ ).

Para evaluar la maduración a partir de embriones en etapa torpedo temprano se realizaron dos experimentos; en el primero, los embriones se cultivaron durante $40 \mathrm{~d}$ en cajas Petri con $15 \mathrm{~mL}$ de los mismos medios utilizados para embriones globulares, con excepción de los que contenían 50 y $60 \mathrm{~g} \mathrm{~L}^{-1}$ de sacarosa (Figura 1C). En el segundo experimento, los embriones torpedo fueron colocados en cajas Petri con medio Yasuda más $2.3 \mathrm{~g} \mathrm{~L}^{-1}$ de Phytagel, 30 $\mathrm{g} \mathrm{L}^{-1}$ de sacarosa y dos combinaciones de reguladores de crecimiento: 1) $0.7 \mathrm{mg} \mathrm{L}^{-1}$ de $\mathrm{AG}_{3}$ y $0.3 \mathrm{mg} \mathrm{L}^{-1}$ de AIA, y 2) $1.0 \mathrm{mg} \mathrm{L}^{-1}$ de $\mathrm{AG}_{3}$ y $0.5 \mathrm{mg} \mathrm{L}^{-1}$ de AIA; ambos experimentos fueron comparados con un testigo que contenía un medio basal Yasuda con $0.2 \mathrm{mg} \mathrm{L}^{-1}$ de BAP, $0.2 \mathrm{mg} \mathrm{L}^{-1}$ de AIA y 30 $\mathrm{g} \mathrm{L}^{-1}$ de sacarosa. 
El pH de todos los medios fue ajustado a 6.3; los cultivos fueron incubados en una cámara de crecimiento a $25 \pm 2{ }^{\circ} \mathrm{C}$ y $16 \mathrm{~h}$ de luz (intensidad lumínica de 80 umol $\left.\mathrm{m}^{-2} \mathrm{~s}^{-1}\right)$. Después de 40 días se evaluó el número de embriones que alcanzaron la etapa torpedo tardío o cotiledonar (embriones maduros); además, se midió el potencial osmótico de los mismos debido a que reportes previos (Márquez-Martín et al., 2011; Martínez et al., 2017) relacionaron la disminución del potencial osmótico de los embriones con su maduración. Para evaluar esta variable, embriones maduros se depositaron en tubos Eppendorf y luego en nitrógeno líquido para extraer el contenido líquido intracelular, el cual fue colocado en un osmómetro Vapro (Wescor Vapor Pressure Osmometer 5520, Champaign, Illinois, EUA). La evaluación del potencial osmótico se basó en cuatro repeticiones por tratamiento, siendo una repetición un tubo con diferente número de embriones. No fue posible determinar el potencial osmótico de los embriones globulares correspondientes a los tratamientos
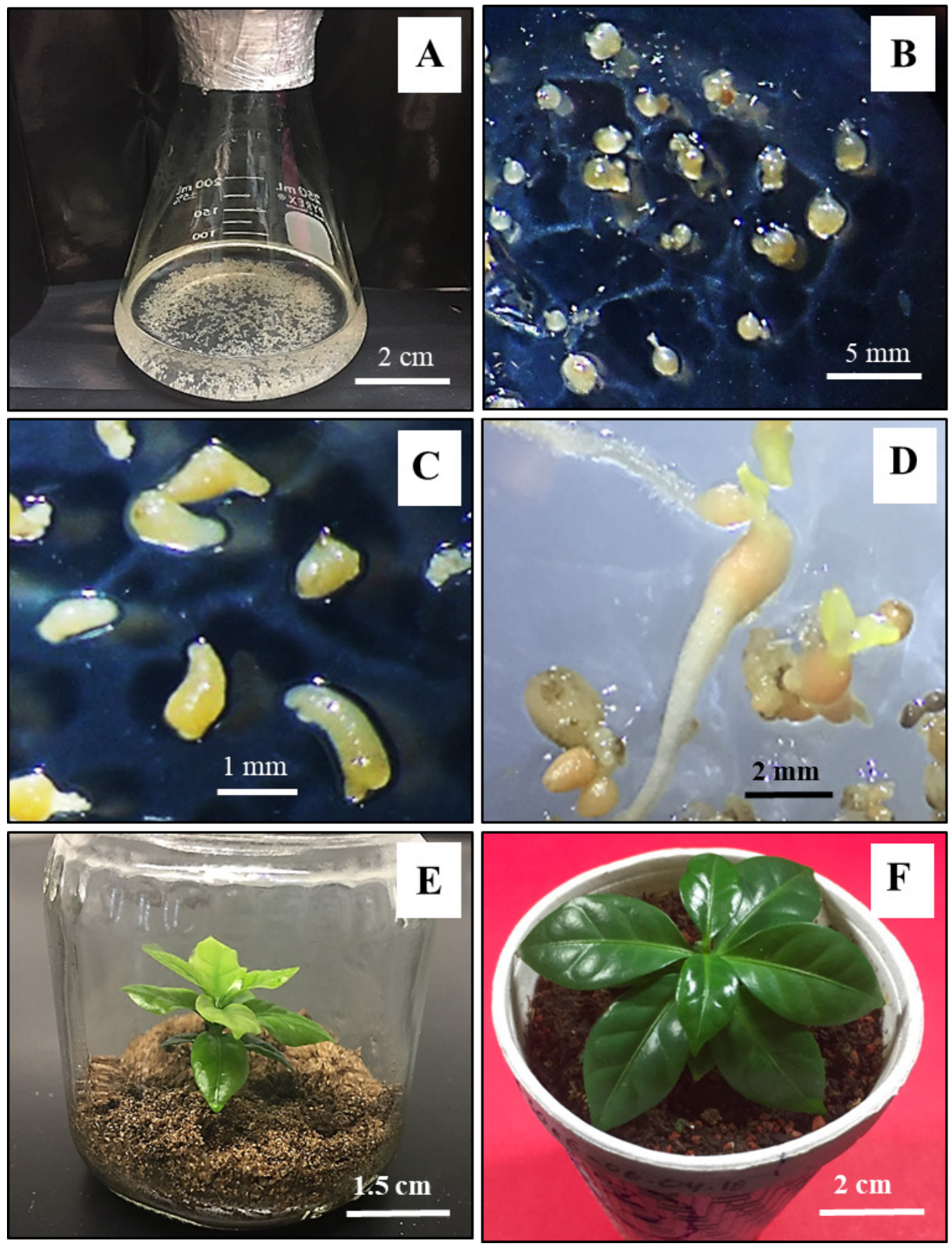

Figura 1. Embriogénesis somática indirecta en $C$. arabica var. Colombia. A) formación de embriones somáticos a partir de callos embriogénicos, B) embriones somáticos en etapa globular, C) embriones somáticos en etapa torpedo temprano, D) germinación de un embrión proveniente de un medio de maduración con $50 \mathrm{~g} \mathrm{~L}^{-1}$ de sacarosa, E) conversión in vitro de una plántula de café en sustrato vermiculita:perlita, F) planta de café después de 90 días de cultivo en invernadero. 
con 50 y $60 \mathrm{~g} \mathrm{~L}^{-1}$ de sacarosa, así como el de los embriones torpedo temprano del segundo experimento, debido a que no se disponía de un número suficiente de éstos.

\section{Germinación de embriones somáticos}

Sólo los embriones que lograron madurar en los tratamientos de maduración fueron cultivados en viales de cristal con $7 \mathrm{~mL}$ de medio de germinación líquido elaborado con las sales basales de Yasuda modificadas, y suplementado con $0.25 \mathrm{mg} \mathrm{L}^{-1}$ de AIA, $0.25 \mathrm{mg} \mathrm{L}^{-1}$ de BAP y $30 \mathrm{~g} \mathrm{~L}^{-1}$ de sacarosa, ajustando el pH del medio a 6.3. Durante esta fase los cultivos permanecieron en un agitador orbital a 100 rpm dentro de una cámara de crecimiento a 25 $\pm 2^{\circ} \mathrm{C}$ y $16 \mathrm{~h}$ de luz (intensidad lumínica de $80 \mu \mathrm{mol} \mathrm{m} \mathrm{m}^{-2} \mathrm{~s}^{-1}$ ). Después de 60 días se determinó el número de embriones somáticos germinados (embriones con protrusión de la radícula y cotiledones extendidos) con respecto al número de embriones que alcanzaron la madurez (Germinación M) y en relación con número inicial de embriones cultivados en los medios de maduración (Germinación I). Los embriones que germinaron se colocaron en frascos con $30 \mathrm{~mL}$ de una mezcla de vermiculita y perlita $(3: 1)$, con tamaño de partícula de $0.25 \mathrm{~mm}$ esterilizada durante $40 \mathrm{~min}$ a $121^{\circ} \mathrm{C}$ para promover su conversión; a la mezcla se agregaron 15 $\mathrm{mL}$ de medio de cultivo MS líquido al $50 \%$ y $20 \mathrm{~g} \mathrm{~L}^{-1}$ de sacarosa, sin reguladores de crecimiento.

\section{Aclimatación y crecimiento de plantas}

Cuando las plantas alcanzaron $2 \mathrm{~cm}$ de longitud y al menos 3 pares de hojas fueron transferidas a vasos de poliestireno de $250 \mathrm{~mL}$ con dos mezclas de sustratos: 1) perlita-turba-tezontle (1:1:1) y 2) turba-tezontle (2:1). Los vasos se llevaron al invernadero y se cubrieron con bolsas de plástico, las cuales fueron retiradas después de 15 días. Las plantas se regaron cada tres días con solución Steiner (1984) al 25 \%. Después de 90 días se evaluó la supervivencia, tamaño de plúmula y número de hojas. Para determinar el comportamiento de las plantas regeneradas en condiciones ex vitro después de $110 \mathrm{~d}$ de cultivo se evaluaron las siguientes variables fisiológicas: área foliar (Antunes et al., 2008), tasa instantánea de fotosíntesis (A), conductancia estomática (gs), transpiración (E) y concentración interna de $\mathrm{CO}_{2}(\mathrm{Ci})$ con ayuda de un analizador de gases en infrarrojo IRGA (LICOR-6400 XT Portable Photosynthesis System, Lincoln, Nebraska, EUA).

\section{Diseño experimental y análisis estadístico}

En los experimentos de maduración se utilizó un diseño experimental completamente al azar (DECA) con 10 medios de maduración (tratamientos) para los embriones globulares y 6 repeticiones (una caja con 30 embriones);
8 medios de maduración para embriones torpedo del primer experimento con 6 repeticiones (una caja con 20 embriones) y 3 medios de maduración para los torpedo del segundo experimento con 6 repeticiones (una caja con 10 embriones). Para la germinación se empleó un DECA desbalanceado con 9 medios de maduración para los embriones globulares, 2 medios de maduración para los embriones torpedo del primer experimento y 2 medios para los torpedo del segundo experimento. Todos los experimentos tuvieron diferente número de repeticiones por tratamiento, siendo una repetición un vial con diferente número de embriones maduros. En las fases de maduración y germinación el análisis de los datos se hizo con regresión logística y la comparación de medias mediante la prueba de LSMeans (0.05) mediante el paquete estadístico SAS versión 9.5 (SAS Institute, 2002). Para la variable potencial osmótico el análisis se llevó a cabo mediante ANOVA y la comparación de medias mediante la prueba de Tukey $(P \leq 0.05)$, mientras que para la fase de aclimatación se usó un DECA con dos sustratos y cuatro repeticiones considerando una planta como una repetición. El análisis de los datos se hizo mediante la prueba $t$ de Student.

\section{RESULTADOS Y DISCUSIÓN}

\section{Efecto de reguladores de crecimiento y osmóticos en la maduración de los embriones somáticos}

Durante la maduración, los embriones somáticos sufren cambios morfológicos y bioquímicos, como el aumento en la talla y la deposición de sustancias de reserva, esenciales para su posterior desarrollo, germinación y conversión en plantas fotoautótrofas (Aslam et al., 2011; Etienne, 2005; Márquez-Martín et al., 2011).

Los resultados obtenidos en la presente investigación mostraron que el porcentaje de maduración de los embriones globulares cultivados en el medio con 2, 3 o $4 \mathrm{mg} \mathrm{L}^{-1}$ de ABA estuvo por debajo (6.7-11.7\%) de lo observado en el testigo (19.4 \%) (Cuadro 1); asimismo, los embriones globulares expuestos a PEG no mostraron porcentajes de maduración significativamente mejores (21.7-25.6 \%) que el testigo (Cuadro 1). Cuando se incluyeron $1.38 \mathrm{~g} \mathrm{~L}^{-1}$ de ASA en el medio de cultivo, sólo 1.7 $\%$ de los embriones lograron madurar; en contraste, 50, 60 $\mathrm{u} 80 \mathrm{~g} \mathrm{~L}^{-1}$ de sacarosa en el medio de cultivo incrementaron significativamente (45.9-81.7\%) la maduración de los embriones globulares con respecto al testigo y a los otros tratamientos, siendo los embriones de los tratamientos con sacarosa los que registraron los niveles más altos de maduración (Cuadro 1).

Por otro lado, los embriones torpedo del primer experimento cultivados en las distintas dosis de ABA y 
ASA mostraron porcentajes de maduración inferiores (0.8$2.5 \%$ ) al testigo (10.0\%), en tanto que el observado en los embriones cultivados en PEG no fue significativamente diferente del testigo. Asimismo, en los embriones torpedo cultivados con $80 \mathrm{~g} \mathrm{~L}^{-1}$ de sacarosa (19.2\%) se registró un porcentaje de maduración significativamente mayor que en aquellos expuestos a las distintas concentraciones de ABA (2.5\%), ASA (0.8\%) y el testigo (Cuadro 1); en contraste, para los embriones torpedo del segundo experimento, el porcentaje de maduración más alto (45\%) se observó con la combinación de $1.0 \mathrm{mg} \mathrm{L}^{-1}$ de $\mathrm{AG}_{3}$ y $0.5 \mathrm{mg} \mathrm{L}^{-1}$ de AlA (Cuadro 1).

González et al. (2000) encontraron que el adicionar 1 $\mathrm{mg} \mathrm{L}^{-1}$ de ABA al medio de cultivo logró generar el mayor porcentaje de maduración (56.1\%) de los embriones somáticos de $C$. canephora var. Robusta; por otro lado, en C. papaya, Kalam et al. (2012) observaron que el mayor porcentaje de maduración y acumulación de materia seca se registró cuando los embriones se cultivaron en presencia de $60 \mathrm{~g} \mathrm{~L}^{-1}$ de PEG 3350; no obstante, algunos autores han reportado que altos niveles de este compuesto (47.0 a $75.0 \mathrm{~g} \mathrm{~L}^{-1}$ ) pueden tener un efecto negativo en la maduración al restringir la acumulación de proteínas LEA (Late embryogenesis abundant), sacarosa y almidón (Businge et al., 2013; Tikkinen et al., 2018).

Etienne (2005) utilizó un medio líquido con $0.3 \mathrm{mg} \mathrm{L}^{-1}$ de BAP y $40 \mathrm{~g} \mathrm{~L}^{-1}$ de sacarosa para inducir la maduración de embriones somáticos de C. canephora var. Robusta y observó que después de ocho semanas 86 \% de éstos alcanzaron la madurez. En Psidium guajava y P. dactylifera, $50 \circ 90 \mathrm{~g} \mathrm{~L}^{-1}$ de sacarosa en el medio de cultivo mejoró la maduración de los embriones (Rai et al., 2007; SghaierHammami et al., 2010); asimismo, el incluir 50 o $60 \mathrm{~g} \mathrm{~L}^{-1}$ de sacarosa en el medio promovió la maduración (60 a 100 \%) de los embriones somáticos de P. abies, Sapindus mukorossi, Agave angustifolia y Crocus vernus (Kubeš et al., 2014; Reyes-Díaz et al., 2017; Singh et al., 2015; Sivanesan et al., 2012). Se sabe que cuando se incluyen concentraciones altas de sacarosa en los medios de cultivo, ésta entra en los tejidos de los embriones y es hidrolizada por la enzima invertasa-apoplástica, promoviendo la deposición de glucosa, fructosa y almidón en el embrión (Iraqi et al., 2005). Lo anterior hace que la presión osmótica del embrión aumente induciendo la expresión de los genes que codifican a la glutamina-sintetasa y glutamato-sintasa, involucradas en el metabolismo del nitrógeno y la deposición de proteínas de almacenamiento como globulinas, prolaminas y glutelinas, requeridas para que el embrión madure y germine (Bartos et al., 2018; Cangahuala-Inocente et al., 2009; Iraqi y Tremblay, 2001; Kubeš et al., 2014; Montalbán et al., 2010; Shewry y Halford, 2002; Stasolla et al., 2003).

Por otro lado, en C. arabica cv. Acaiá, Pereira et al. (2007) observaron un incremento en la maduración de los embriones (9-38 embriones maduros) directamente proporcional al aumento en la concentración de $\mathrm{AG}_{3}(2.5-$ $\left.20 \mathrm{mg} \mathrm{L}^{-1}\right)$; asimismo, la maduración de los embriones

Cuadro 1. Porcentaje de embriones maduros globulares y torpedo temprano de $C$. arabica var. Colombia cultivados en distintos tratamientos de maduración durante 40 días.

\begin{tabular}{|c|c|c|c|}
\hline Medio de maduración & Embriones globulares & $\begin{array}{l}\text { Embriones torpedo } \\
\text { (Primer experimento) }\end{array}$ & $\begin{array}{c}\text { Embriones torpedo } \\
\text { (Segundo experimento) }\end{array}$ \\
\hline Testigo & $19.4 \pm 16.0 \mathrm{~d}$ & $10.0 \pm 12.0 \mathrm{~b}$ & $5.0 \pm 9.0 b$ \\
\hline ABA $2 \mathrm{mg} \mathrm{L}^{-1}$ & $11.7 \pm 13.0 \mathrm{e}$ & $2.5 \pm 6.0 c$ & -- \\
\hline ABA $3 \mathrm{mg} \mathrm{L}^{-1}$ & $6.7 \pm 10.0 \mathrm{e}$ & $2.5 \pm 6.0 c$ & -- \\
\hline ABA $4 \mathrm{mg} \mathrm{L}^{-1}$ & $8.9 \pm 12.0 \mathrm{e}$ & $2.5 \pm 6.0 c$ & -- \\
\hline PEG $800050 \mathrm{~g} \mathrm{~L}^{-1}$ & $25.6 \pm 18.0 d$ & $11.7 \pm 13.0 \mathrm{ab}$ & -- \\
\hline PEG $800075 \mathrm{~g} \mathrm{~L}^{-1}$ & $21.7 \pm 17.0 \mathrm{~d}$ & $15.8 \pm 15.0 a b$ & -- \\
\hline ASA $1.38 \mathrm{~g} \mathrm{~L}^{-1}$ & $1.7 \pm 5.0 f$ & $0.8 \pm 4.0 c$ & -- \\
\hline Sacarosa $50 \mathrm{~g} \mathrm{~L}^{-1}$ & $81.7 \pm 16.0 \mathrm{a}$ & -- & -- \\
\hline Sacarosa $60 \mathrm{~g} \mathrm{~L}^{-1}$ & $67.8 \pm 19.0 \mathrm{~b}$ & -- & -- \\
\hline Sacarosa $80 \mathrm{~g} \mathrm{~L}^{-1}$ & $45.9 \pm 20.0 c$ & $19.2 \pm 16.0 \mathrm{a}$ & -- \\
\hline $\begin{array}{l}0.7 \mathrm{mg} \mathrm{L}^{-1} \mathrm{AG}_{3}+ \\
0.3 \mathrm{mg} \mathrm{L}^{-1} \mathrm{AlA}^{-}\end{array}$ & -- & -- & $15.0 \pm 15.0 b$ \\
\hline $\begin{array}{l}1.0 \mathrm{mg} \mathrm{L}^{-1} \mathrm{AG}_{3}+ \\
0.5 \mathrm{mg} \mathrm{L}^{-1} \mathrm{AlA}^{-}\end{array}$ & -- & -- & $45.0 \pm 20.0 a$ \\
\hline
\end{tabular}

Testigo: $30 \mathrm{~g} \mathrm{~L}^{-1}$ de sacarosa, ABA: ácido abscísico, PEG 8000: polietilenglicol 8000, ASA: ácido salicílico, AIA: ácido indolacético, AG: ácido giberélico. Medias ( \pm error estándar) con letras iguales dentro de una columna no son estadísticamente diferentes (LSMeans, $\mathrm{P} \leq 0.05$ ). 
de Citrus reticulata Blanco aumentó (4-6 \%) cuando se adicionaron al medio $4 \mathrm{mg} \mathrm{L}^{-1}$ de $\mathrm{AG}_{3}$ (Firdiana et al., 2015). Por su parte, da Silva et al. (2018) registraron 50 $\%$ de embriones maduros de Byrsonima intermedia al exponerlos a $10 \mathrm{mg} \mathrm{L}^{-1}$ de $\mathrm{AG}_{3}$.

La diferencia en la respuesta de maduración entre las dos etapas embrionarias evaluadas en C. arabica var. Colombia (globular y torpedo) puede ser debida a los tipos de células presentes en los embriones. QuirozFigueroa et al. (2002) mencionaron que los embriones globulares presentan alta actividad mitótica que permite el crecimiento y desarrollo embrionario, mientras que en embriones torpedo y cotiledonares existen células con un grado de diferenciación mayor. De la misma manera, se ha observado que los niveles de proteínas, carbohidratos y de reguladores de crecimiento endógenos de los embriones en estado globular y torpedo cultivados bajo las mismas condiciones son diferentes, lo cual puede ocasionar una respuesta diferencial a las condiciones de cultivo (Bartos et al. 2018). El hecho de que en la presente investigación mayor número de embriones globulares que de embriones torpedo temprano haya alcanzado la madurez indica que es mejor inducir la maduración, desde la etapa globular, reduciendo con ello tiempo, insumos y mano de obra necesarios.

\section{Efecto de reguladores de crecimiento y osmóticos en el potencial osmótico de embriones somáticos}

Algunos autores afirman que una disminución del potencial osmótico de los embriones somáticos induce cambios morfológicos y bioquímicos que promueven la maduración (Márquez-Martín et al., 2011; Martínez et al., 2017). En la presente investigación no se encontraron diferencias significativas entre el potencial osmótico de los embriones globulares sometidos a los distintos tratamientos con ABA, PEG, ASA, sacarosa (-2.28 a $-3.10 \mathrm{MPa}$ ) y el testigo (-2.13 MPa) (Cuadro 2). Para los embriones torpedo (primer experimento) se registró una variación en el potencial osmótico de -1.54 a -2.37 MPa para los distintos tratamientos, sin ser significativamente diferentes del testigo (-1.83 MPa) (Cuadro 2). Aun cuando no hubo diferencias significativas en los potenciales osmóticos de los embriones globulares y torpedo (primer experimento) expuestos a los distintos tratamientos, sí se observaron diferencias en los porcentajes de maduración, encontrándose el valor más alto en los embriones globulares cultivados en presencia de 50 a $80 \mathrm{~g} \mathrm{~L}^{-1}$ de sacarosa (Cuadro 1). Al respecto, Reyes-Díaz et al. (2017) señalaron que en el medio de maduración la sacarosa en altas concentraciones funciona como fuente de energía y como regulador osmótico, pudiendo mejorar la maduración y el desarrollo de los embriones somáticos. En el mismo tenor, Elmaghrabi et al. (2017) encontraron que exponer embriones somáticos de Medicago truncatula a $100 \mathrm{~g} \mathrm{~L}^{-1}$ de PEG 6000 no causó cambios en el potencial osmótico celular, pero sí generó diferencias en su desarrollo. Otros autores señalan que los agentes osmóticos, como el PEG incluídos, en los medios de cultivo hacen más negativo el potencial osmótico de los embriones induciendo cambios en la división celular, morfología celular, adquisición de la tolerancia al estrés, así como en la expresión de genes relacionados con el desarrollo de los embriones como el SERK1 (cinasa receptora en la embriogénesis somática) (Elmaghrabi et al., 2013).

\section{Efecto de reguladores de crecimiento y osmóticos en la germinación de embriones somáticos}

En esta fase no se consideraron los tratamientos con bajo número de embriones que alcanzaron la madurez. La germinación de los embriones globulares que lograron madurar (Germinación M) provenientes de los medios con distintas dosis de ABA (14.3-25.0 \%) fue inferior al testigo (60.0\%); la misma respuesta se observó con los embriones globulares que se expusieron a PEG (6.5-7.7 \%) (Cuadro 3). Los bajos porcentajes de germinación de los embriones de la variedad Colombia expuestos a PEG 8000 concuerdan con los resultados de Rudiyanto et al. (2014), quienes observaron que al utilizar concentraciones de PEG superiores a $50 \mathrm{~g} \mathrm{~L}^{-1}$ la maduración de los embriones somáticos de Jatropha curcas se inhibió; posiblemente, el PEG a las concentraciones probadas generó un estrés osmótico por arriba de lo que los embriones soportaban, lo cual evitó que éstos pudieran continuar con su desarrollo y acumularan sustancias de reserva necesarias para la germinación (Carlsson et al., 2019).

La germinación de los embriones globulares que maduraron (Germinación M), los cuales permanecieron en presencia de 50 a $80 \mathrm{~g} \mathrm{~L}^{-1}$ de sacarosa (38.3-66.0\%), no fue significativamente diferente de la observada en el testigo (60.0\%); no obstante, cuando se calculó la germinación considerando el número de embriones iniciales en el medio de maduración (Germinación I), tanto el tratamiento con $50 \mathrm{~g} \mathrm{~L}^{-1}(53.9 \%)$ como con $60 \mathrm{~g} \mathrm{~L}^{-1}(29.4 \%)$ de sacarosa fueron significativamente superiores al testigo (11.7\%) y a los demás tratamientos (Cuadro 3; Figura 1D).

Martínez et al. (2015) señalaron que la sacarosa (60 $\left.\mathrm{g} \mathrm{L}^{-1}\right)$ fue un factor importante en el desarrollo de los embriones de Quercus rubra, al promover el incremento en tamaño y la acumulación de almidón en sus cotiledones; asimismo, Montalbán et al. (2010) encontraron que $80 \%$ de los embriones somáticos de Pinus radiata lograrón germinar cuando se adicionaron $60 \mathrm{~g} \mathrm{~L}^{-1}$ de sacarosa al medio de maduración; en contraste, Jalali et al. (2017) registraron 


\begin{tabular}{|c|c|c|}
\hline \multirow{2}{*}{$\begin{array}{l}\text { Medio de } \\
\text { maduración }\end{array}$} & $\begin{array}{l}\text { Embriones } \\
\text { globulares }\end{array}$ & $\begin{array}{c}\text { Embriones torpedo } \\
\text { temprano } \\
\text { (Primer experimento) }\end{array}$ \\
\hline & $\begin{array}{c}\text { Potencial } \\
\text { osmótico } \\
(\mathrm{MPa})\end{array}$ & $\begin{array}{l}\text { Potencial osmótico } \\
(\mathrm{MPa})\end{array}$ \\
\hline Testigo & $-2.13 \pm 0.63 a$ & $-1.83 \pm 0.39 a$ \\
\hline ABA $2 \mathrm{mg} \mathrm{L}^{-1}$ & $-2.78 \pm 0.19 a$ & $-2.37 \pm 0.39 a$ \\
\hline ABA $3 \mathrm{mg} \mathrm{L}^{-1}$ & $-2.91 \pm 0.33 a$ & $-1.71 \pm 0.27 \mathrm{a}$ \\
\hline ABA 4 mg L-1 & $-2.28 \pm 0.82 \mathrm{a}$ & $-1.54 \pm 0.10 a$ \\
\hline PEG $800050 \mathrm{~g} \mathrm{~L}^{-1}$ & $-2.57 \pm 0.61 a$ & $-2.01 \pm 0.76 a$ \\
\hline PEG $800075 \mathrm{~g} \mathrm{~L}^{-1}$ & $-2.93 \pm 2.35 a$ & $-2.01 \pm 0.36 a$ \\
\hline ASA $1.38 \mathrm{~g} \mathrm{~L}^{-1}$ & $-3.10 \pm 0.29 a$ & $-2.27 \pm 0.59 a$ \\
\hline Sacarosa $50 \mathrm{~g} \mathrm{~L}^{-1}$ & -- & -- \\
\hline Sacarosa $60 \mathrm{~g} \mathrm{~L}^{-1}$ & -- & -- \\
\hline Sacarosa $80 \mathrm{~g} \mathrm{~L}^{-1}$ & $-2.31 \pm 0.52 \mathrm{a}$ & $-2.23 \pm 0.56 a$ \\
\hline
\end{tabular}

Testigo: $30 \mathrm{~g} \mathrm{~L}^{-1}$ de sacarosa, ABA: ácido abscísico, PEG 8000: polietilenglicol 8000, ASA: ácido salicílico. Medias ( \pm error estándar) con letras iguales dentro de una columna no son estadísticamente diferentes (LSMeans, $\mathrm{P} \leq 0.05$ ).

sólo 14.9 \% de germinación en Schisandra chinensis cuando los embriones se expusieron a $60 \mathrm{~g} \mathrm{~L}^{-1}$ de sacarosa, en tanto que en Tagetes erecta la germinación máxima (67.5\%) se observó en medios con $45 \mathrm{~g} \mathrm{~L}^{-1}$ de sacarosa (Vanegas et al., 2017).

La germinación de los embriones torpedo del primer experimento, que provenían del tratamiento con $80 \mathrm{~g} \mathrm{~L}^{-1}$ de sacarosa y que alcanzaron la madurez (73.9\%), estuvo por debajo de la observada en el testigo (100.0 \%) (Germinación M) (Cuadro 3), en tanto que la observada en los embriones torpedo del segundo experimento $\left(1 \mathrm{mg} \mathrm{L}^{-1}\right.$ de $\mathrm{AG}_{3}+0.5 \mathrm{mg}$ $\mathrm{L}^{-1}$ de AIA) (44.4\%) no fue significativamente distinta del testigo (66.7 \%) cuando sólo se consideraron los embriones maduros (Germinación M), ni cuando se calculó con respecto al número inicial de embriones (Germinación I) (Cuadro 3). Carlsson et al. (2019) afirmaron que sólo los embriones que hayan acumulado suficientes sustancias de reserva en la maduración tendrán la capacidad de germinar y convertirse en plantas. De lo anterior, se puede inferir que la capacidad de germinación de los embriones de café está en función de su grado de madurez.

\section{Efecto de los sustratos en la aclimatación y crecimiento de las plantas}

\section{Supervivencia, tamaño de plúmula y número de hojas}

Después de 90 días en condiciones de invernadero todas las plantas sobrevivieron en ambos sustratos (Figura 1F) Los resultados encontrados en este estudio son similares a los de Kahia et al. (2016), quienes registraron $98 \%$ de supervivencia en vitroplantas de $C$. arabica cultivadas en suelo y estiércol (3:1) durante 30 días. Por otro lado, no se observaron diferencias significativas en el tamaño de la plúmula de las plantas cultivadas en perlita:turba:tezontle $(4.9 \mathrm{~cm})$ con respecto a las que fueron cultivadas en turba:tezontle $(4.5 \mathrm{~cm})$. El tamaño alcanzado por las plantas de C. arabica var. Colombia fue similar al de las plantas de $C$. arabica var. Catuaí cultivadas en turba o en suelo (4.8 y $5.4 \mathrm{~cm}$, respectivamente) (Gawad et al., 2012; Isaac et al. 2014). Las diferencias observadas pueden deberse, por un lado, a que la variedad Colombia es de porte bajo y crecimiento lento (López-García et al., 2016), y por otro, a las condiciones climáticas del sitio del experimento (Texcoco, Estado de México), las cuales no son óptimas para cultivar café. Asimismo, el número de hojas de las plantas cultivadas en perlita:turba:tezontle (15.5) no fue significativamente distinto del de aquellas crecidas en turba:tezontle (14.5), pero sí mayor al reportado por Gawad et al. (2012) (3.3-3.67) en plantas de la var. Catuaí.

\section{Intercambio de gases y área foliar}

Debido a que las condiciones heterotróficas durante el cultivo in vitro pueden causar alteraciones fisiológicas en las plantas y afectar su comportamiento en condiciones ex vitro (Chandra et al., 2010; Kumar y Rao, 2012) y a que el tipo de sustrato también influye en dicho comportamiento (Afreen et al., 2002; Aga y Khillare, 2017; Maciel et al., 2016), se midió el intercambio de gases durante la fotosíntesis, así como el área foliar de las plantas regeneradas cultivadas en las dos mezclas de sustratos.

La tasa fotosintética de las plantas crecidas en perlita:turba:tezontle no fue significativamente mayor que la encontrada en las plantas cultivadas en turba:tezontle (Cuadro 4). Es importante mencionar que en el presente trabajo la radiación al momento de las mediciones fue

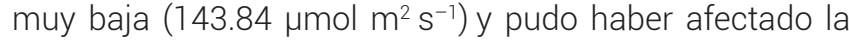
tasa fotosintética. Li et al. (2015) mencionaron que la actividad fotosintética depende de factores ambientales como la radiación interceptada por el dosel y que cuando ésta es baja, la tasa fotosintética se reduce. En cuanto a la conductancia estomática, ésta fue de $0.11 \mu \mathrm{mol} \mathrm{H}_{2} \mathrm{O}$ $\mathrm{m}^{-2} \mathrm{~s}^{-1}$ en las plantas cultivadas en perlita:turba:tezontle, valor significativamente superior al encontrado en aquellas crecidas en turba:tezontle (Cuadro 4); lo anterior indica que en estas últimas hubo un menor intercambio gaseoso. Por su parte, la concentración interna de $\mathrm{CO}_{2}$ de las plantas cultivadas en perlita:turba:tezontle fue significativamente superior (369.72 $\mathrm{mmol} \mathrm{CO}_{2} \mathrm{~mol}^{-1}$ ) a la registrada en las plantas crecidas en turba:tezontle 
Cuadro 3. Germinación de embriones somáticos de $C$. arabica var. Colombia después de 60 días de cultivo en el medio de germinación.

\begin{tabular}{|c|c|c|c|c|c|c|}
\hline \multirow{2}{*}{$\begin{array}{l}\text { Medio de } \\
\text { maduración }\end{array}$} & \multicolumn{2}{|c|}{ Embriones globulares } & \multicolumn{2}{|c|}{$\begin{array}{l}\text { Embriones torpedo temprano } \\
\text { (Primer experimento) }\end{array}$} & \multicolumn{2}{|c|}{$\begin{array}{c}\text { Embriones torpedo temprano } \\
\text { (Segundo experimento) }\end{array}$} \\
\hline & $\begin{array}{l}\text { Germinación } \\
\mathrm{M}^{+}(\%)\end{array}$ & $\begin{array}{c}\text { Germinación } \\
\left.\right|^{++}(\%)\end{array}$ & $\begin{array}{c}\text { Germinación } \\
M(\%)\end{array}$ & $\begin{array}{l}\text { Germinación } \\
\text { I (\%) }\end{array}$ & $\begin{array}{l}\text { Germinación } \\
\text { M (\%) }\end{array}$ & $\begin{array}{l}\text { Germinación } \\
\text { I (\%) }\end{array}$ \\
\hline Testigo & $60.0 \pm 22.0 \mathrm{ab}$ & $11.7 \pm 13.0 \mathrm{c}$ & $100 \pm 0.00 \mathrm{a}$ & $10.0 \pm 12.0 \mathrm{a}$ & $66.7 \pm 33.0 \mathrm{a}$ & $3.3 \pm 7.0 \mathrm{a}$ \\
\hline ABA $2 \mathrm{mg} \mathrm{L}^{-1}$ & $14.3 \pm 16.0 \mathrm{~d}$ & $1.7 \pm 5.0 \mathrm{~d}$ & -- & -- & -- & -- \\
\hline ABA $3 \mathrm{mg} \mathrm{L}^{-1}$ & $25.0 \pm 19.0 \mathrm{~cd}$ & $1.7 \pm 5.0 \mathrm{~d}$ & -- & -- & -- & -- \\
\hline ABA $4 \mathrm{mg} \mathrm{L}^{-1}$ & $18.3 \pm 16.0 \mathrm{~cd}$ & $1.7 \pm 5.0 \mathrm{~d}$ & -- & -- & -- & -- \\
\hline PEG $800050 \mathrm{~g} \mathrm{~L}^{-1}$ & $6.5 \pm 14.0 \mathrm{~d}$ & $1.7 \pm 5.0 \mathrm{~d}$ & -- & -- & -- & -- \\
\hline PEG $800075 \mathrm{~g} \mathrm{~L}^{-1}$ & $7.7 \pm 15.0 \mathrm{~d}$ & $1.7 \pm 5.0 \mathrm{~d}$ & -- & -- & -- & -- \\
\hline Sacarosa $50 \mathrm{~g} \mathrm{~L}^{-1}$ & $66.0 \pm 19.0 \mathrm{a}$ & $53.9 \pm 20.0 \mathrm{a}$ & -- & -- & -- & -- \\
\hline Sacarosa $60 \mathrm{~g} \mathrm{~L}^{-1}$ & $43.4 \pm 20.0 \mathrm{bc}$ & $29.4 \pm 19.0 b$ & -- & -- & -- & -- \\
\hline Sacarosa $80 \mathrm{~g} \mathrm{~L}^{-1}$ & $38.3 \pm 20.0 \mathrm{bc}$ & $17.2 \pm 15.0 \mathrm{c}$ & $73.9 \pm 20.0 b$ & $14.2 \pm 14.0 \mathrm{a}$ & -- & -- \\
\hline $\begin{array}{l}1.0 \mathrm{mg} \mathrm{L}^{-1} \mathrm{AG}_{3}+ \\
0.5 \mathrm{mg} \mathrm{L}^{-1} \mathrm{AlA}^{-}\end{array}$ & -- & -- & -- & -- & $44.4 \pm 20.0 \mathrm{a}$ & $20.0 \pm 28.0 \mathrm{a}$ \\
\hline
\end{tabular}

(Cuadro 4); lo anterior pudo deberse a que en estas últimas hubo menor conductancia estomática y menor entrada de $\mathrm{CO}_{2^{\prime}}$ agotándose el $\mathrm{CO}_{2}$ interno.

En café, se han realizado estudios para la estimación del área foliar en plantas adultas obtenidas por semilla; por ello, fue necesario estimar el cociente largo/ancho relacionado con el área foliar. En el Cuadro 4 se muestra que no hubo diferencias significativas en el valor del cociente entre el promedio del largo y el promedio del ancho de las hojas de ambos tratamientos; de igual manera, se observa que el área foliar de las plantas crecidas en turba:tezontle $\left(24.99 \mathrm{~cm}^{2}\right)$ no fue significativamente superior al de las plantas crecidas en perlita:turba:tezontle $\left(24.07 \mathrm{~cm}^{2}\right)$. Al respecto, el área foliar de plantas de C. arabica var. Castillo provenientes de semilla, cultivadas en campo, fue similar $(26.7 \mathrm{~cm})$ al observado en las plantas de la var. Colombia (24.99 cm) (Unigarro-Muñoz et al., 2015). Lo anterior indica que las condiciones de cultivo probadas en la presente investigación permitieron regenerar plantas fisiológicamente funcionales con características similares a las plantas obtenidas a partir de semilla, lo cual es deseable en un programa de propagación a escala comercial.

Diversos protocolos sobre embriogénesis somática de café han sido desarrollados (Aga y Khillare, 2017; Etienne et al. 2013; 2018; Gatica-Arias et al., 2008; Georget et al., 2017; Kahia et al., 2016; Montes-Cruz et al., 2017); no obstante, para la variedad Colombia sólo se conoce un reporte (Avila-Victor et al., 2018), en el cual los aspectos relacionados con la maduración y germinación de los embriones somáticos se abordaron someramente; asimismo, existe evidencia de que la respuesta al cultivo in vitro depende del genotipo, por lo que las condiciones de cultivo deberán establecerse para cada variedad (LópezGómez et al., 2010; Santana-Buzzy et al., 2007).

Cuadro 4. Comparación de medias de componentes del intercambio gaseoso entre sustratos de aclimatación.

\begin{tabular}{lcccccc}
\hline Sustrato & $\mathrm{A}$ & gs & $\mathrm{E}$ & $\mathrm{Ci}$ & $\begin{array}{c}\text { Cociente } \\
\text { largo/ancho }\end{array}$ & Área foliar $\left(\mathrm{cm}^{2}\right)$ \\
\hline PTT & $1.51 \mathrm{~ns}$ & $0.11 *$ & $2.45 *$ & $369.72 *$ & $2.0 \mathrm{~ns}$ & 24.07 \\
TT & 1.88 & 0.06 & 1.48 & 330.14 & 2.0 & $24.99 \mathrm{~ns}$ \\
\hline
\end{tabular}

PTT: perlita-turba-tezontle, TT: turba-tezontle, A: tasa fotosintética ( $\left.\mu \mathrm{mol} \mathrm{CO}_{2} \mathrm{~m}^{-2} \mathrm{~s}^{-1}\right)$, gs: conductancia estomática $\left(\mu \mathrm{mol} \mathrm{H}_{2} \mathrm{O} \mathrm{m}^{-2} \mathrm{~s}^{-1}\right)$, E: transpiración ( $\left.\mathrm{mmol} \mathrm{H} \mathrm{O} \mathrm{m}^{-2} \mathrm{~s}^{-1}\right)$, Ci: concentración interna de $\mathrm{CO}_{2}\left(\mathrm{mmol} \mathrm{CO}_{2} \mathrm{~mol}^{-1}\right)$. Datos tomados a los 110 días después de cultivo; ns: diferencias no significativas, $*$ : diferencias significativas ( $t$-Student, $P \leq 0.05$ ). 
La baja tasa de maduración, geminación y conversión limita la aplicación de los protocolos de embriogénesis en los programas de producción de plantas a escala comercial, tanto en la var. Colombia como en otras especies y cultivares de café, por lo que se requieren más estudios al respecto (Carlsson et al., 2019). Los resultados obtenidos en el presente estudio proveen información para la optimización de protocolos de multiplicación de $C$. arabica var. Colombia mediante embriogénesis somática.

\section{CONCLUSIONES}

Altas concentraciones de sacarosa (50-80 $\left.\mathrm{g} \mathrm{L}^{-1}\right)$ en el medio de cultivo aumentan significativamente la tasa de maduración de embriones somáticos globulares y torpedo temprano de C. arabica var. Colombia. El inducir la maduración de los embriones desde la etapa globular puede reducir el tiempo, insumos y mano de obra requeridos. El potencial osmótico de los embriones no tiene relación directa con su maduración. El grado de madurez de los embriones somáticos influye en su capacidad para germinar y convertirse en plantas. Las plantas regeneradas son morfológica y fisiológicamente normales bajo condiciones ex vitro y tienen alta capacidad para adaptarse a dichas condiciones.

\section{AGRADECIMIENTOS}

Al Consejo Nacional de Ciencia y Tecnología por la beca otorgada a Enrique Riviello Cogco para realizar sus estudios de Maestría (813933).

\section{BIBLIOGRAFÍA}

Afreen F., S. Zobayed and T. Kozai (2002) Photoautotrophic culture of Coffea arabusta somatic embryos: development of a bioreactor for largescale plantlet conversion from cotyledonary embryos. Annals of Botany 90:21-29, https://doi.org/10.1093/aob/mcf151

Aga E. and Y. Khillare (2017) In vitro multiplication of Coffea arabica L. from leaf explants through indirect somatic embryogenesis. International Journal of Botany Studies 2:17-22.

Antunes W. C., F. M. Pompelli, M. D. Carretero and M. F. DaMatta (2008) Allometric models for non-destructive leaf area estimation in coffee (Coffea arabica and Coffea canephora). Annals of Applied Biology 153:33-40, https://doi:10.1111/j.1744-7348.2008.00235.x

Aslam J., K. S. Ahmad, C. A. Jaleel, A. Mujib, S. M. Pershad and S. P. Shanker (2011) Somatic embryogenesis, scanning electron microscopy, histology and biochemical analysis at different developing stages of embryogenesis in six date palm (Phoenix dactylifera L.) cultivars. Saudi Journal of Biological Sciences 18:369-380, https://doi:10.1016/j.sjbs.2011.06.002

Avila-Victor C. M., Á. Martínez-Infante, V. M. Ordaz-Chaparro, E. J. ArjonaSuárez, L. Iracheta-Donjuan, F. C. Gómez-Merino y A. Robledo-Paz (2018) Embriogénesis somática directa e indirecta en Coffea arabica var. Colombia. Agroproductividad 11:30-35.

Bartos P. M. C., H. T. Gomes, L. I. V. do Amaral, J. B. Teixeira and J. E. Scherwinski-Pereira (2018) Biochemical events during somatic embryogenesis in Coffea arabica L. 3 Biotech 8:209, https://doi.org/10.1007/s13205-018-1238-7

Businge E., J. Bygdell, G. Wingsle, T. Moritz and U. Egertsdotter (2013) The effect of carbohydrates and osmoticum on storage reserve accumulation and germination of Norway spruce somatic embryos. Physiologia Plantarum 149:273-285, https://doi.org/10.1111/ppl.12039

Campos N. A., B. Panis and S. C. Carpentier (2017) Somatic embryogenesis in coffee: the evolution of biotechnology and the integration of omics technologies offer great opportunities. Frontiers in Plant Science 8:1460, https://doi.org/10.3389/fpls.2017.01460

Cangahuala-Inocente G. C., N. Steiner, S. B. Maldonado and M. P. Guerra (2009) Patterns of protein and carbohydrate accumulation during somatic embryogenesis of Acca sellowiana. Pesquisa Agropecuária Brasileira 44:217-224, https://doi.org/10.1590/S0100-204X2009000300001

Carlsson J., U. Egertsdotter, U. Ganeteg and H. Svennerstam (2019) Nitrogen utilization during germination of somatic embryos of Norway spruce: revealing the importance of supplied glutamine for nitrogen metabolism. Trees 33:383-394, https://doi.org/10.1007/s00468-018-1784-y

Chandra S., R. Bandopadhyay, V. Kumar and R. Chandra (2010) Acclimatization of tissue cultured plantlets: from laboratory to land. Biotechnology Letters 32:1199-1205, https://doi.org/10.1007/s10529-010-0290-0

da Silva D. P. C., R. Paiva, R. C. Herrera, L. C. Silva, G. N. Ferreira and M. V. dos Reis (2018) Somatic embryogenesis of Byrsonima intermedia A. Juss.: induction and maturation via indirect approach. Plant Cell, Tissue and Organ Culture 133:115122, https://doi.org/10.1007/s11240-017-1366-5

Elmaghrabi A. M., S. Ochatt, H. J. Rogers and D. Francis (2013) Enhanced tolerance to salinity following cellular acclimation to increasing $\mathrm{NaCl}$ levels in Medicago truncatula. Plant Cell, Tissue and Organ Culture 114:61-70, https://doi.org/10.1007/s11240-013-0306-2

Elmaghrabi A. M., H. J. Rogers, D. Francis and S. J. Ochatt (2017) PEG induces high expression of the cell cycle checkpoint gene WEE7 in embryogenic callus of Medicago truncatula: potential link between cell cycle checkpoint regulation and osmotic stress. Frontiers in Plant Science 8:1479, https://doi.org/10.3389/fpls.2017.01479

Etienne H (2005) Somatic embryogenesis protocol: coffee (Coffea arabica L. and C. canephora P.). In: Protocol for Somatic Embryogenesis in Woody Plants. Forestry Sciences Vol 77. S. M Jain and P. K. Gupta (eds.). Springer. Dordrecht, The Netherlands. pp:167-179, https://doi.org/10.1007/1-4020-2985-3_14

Etienne H., B. Bertrand, F. Georget, M. Lartaud, F. Montes, E. Dechamp, ... and D. Barry-Etienne (2013) Development of coffee somatic and zygotic embryos to plants differs in the morphological, histochemical and hydration aspects. Tree Physiology 33:640-653, https://doi.org/10.1093/treephys/tpt034

Etienne H., D. Breton, J. C. Breitler, B. Bertrand, E. Déchamp, R. Awada, ... and J. C. Ducos (2018) Coffee somatic embryogenesis: how did research, experience gained and innovations promote the commercial propagation of elite clones from the two cultivated species? Frontiers in Plant Science 9:1630 https://doi.org/10.3389/fpls.2018.01630

Firdiana E. R., S. Indriyani and W. Widoretno (2015) The Effect of gibberellin on somatic embryo growth and maturation and plantlet regeneration of tangerine (Citrus reticulata Blanco.) var. Batu 55. Journal of Experimental Life Science 5:19-23, https://doi.org/10.21776/ub.jels.2015.005.01.04

Gatica-Arias A. M., G. Arrieta-Espinoza and A. M. Espinoza E. (2008) Plant regeneration via indirect somatic embryogenesis and optimisation of genetic transformation in Coffea arabica L. cvs. Caturra and Catuaí. Electronic Journal of Biotechnology 11:101-112 https://doi.org/10.2225/vol11-issue1-fulltext-9

Gawad E. A., M. A. Nehad, H. A. Mahdy and E. S. Boshra (2012) In vitro micropropagation protocol and acclimatization of coffee trees (Coffea arabica L.). Journal of Plant Production 3:109-116, https://doi.org/10.21608/JPP.2012.84031

Georget F., P. Courtel, E. M. Garcia, M. Hidalgo, E. Alpizar, J. C. Breitler, ... and H. Etienne (2017) Somatic embryogenesis-derived coffee plantlets can be efficiently propagated by horticultural rooted mini-cuttings: a boost for somatic embryogenesis. Scientia Horticulturae 216:177-185, https://doi.org/10.1016/j.scienta.2016.12.017

González M. E., R. Ramos y N. Santana (2000) Efecto del ácido abscísico (ABA) en la regulación del desarrollo de embriones somáticos de Coffea canephora P. var. Robusta. Cultivos Tropicales 21:33- 
37.

Hazubska-Przybył T., E. M. Kalemba, E. Ratajczak and K. Bojarczuk (2016) Effects of abscisic acid and an osmoticum on the maturation, starch accumulation and germination of Picea spp. somatic embryos. Acta Physiologiae Plantarum 38:59, http://doi.org/10.1007/s11738-016-2078-x

Iraqi D. and F. M. Tremblay (2001) Analysis of carbohydrate metabolism enzymes and cellular contents of sugars and proteins during spruce somatic embryogenesis suggests a regulatory role of exogenous sucrose in embryo development. Journal of Experimental Botany 52:2301-2311, https://doi.org/10.1093/jexbot/52.365.2301

IraqiD., M. S. Lamhamediand F. M. Tremblay(2005) Sucrose utilization during somatic embryo development in black spruce: involvement of apoplastic invertase in the tissue and of extracellular invertase in the medium. Journal of Plant Physiology 162:115-124, https://doi.org/10.1016/j.jplph.2003.06.001

Isaac A. E., A. Mbogholi, Y. F. Boix, J. González-Olmedo and A. Chalfun-Junior (2014) Effects of EMFs on some biological parameters in coffee plants (Coffea arabica L.) obtained by in vitro propagation. Polish Journal of Environmental Studies 23:95-101.

Jalali M. A., H. B. Sirmandi and A. Hatamzadeh (2017) Effects of carbohydrate source and polyethylene glycol on maturation and germination of somatic embryos in walnut (Juglans regia L.). Journal of Crop Science and Biotechnology 20:29-35, https://doi.org/10.1007/s12892-016-00089-1

Kahia J., M. Kirika, H. Lubabali and S. Mantell (2016) High-frequency direct somatic embryogenesis and plantlet regeneration from leaves derived from in vitro-germinated seedlings of a Coffea arabica hybrid cultivar. HortScience 51:1148-1152, https://doi.org/10.21273/HORTSCI10771-16

Kalam A. M. A., G. Rabbani and L. Amin (2012) Plant regeneration and somatic embryogenesis from immature embryos derived through interspecific hybridization among different Carica species. International Journal of Molecular Sciences 13:1706517076, https://doi:10.3390/ijms131217065

Kubeš M., N. Drážná, H. Konrádová and H. Lipavská (2014) Robust carbohydrate dynamics based on sucrose resynthesis in developing Norway spruce somatic embryos at variable sugar supply. In Vitro Cellular and Developmental Biology-Plant 50:45-57, https://doi.org/10.1007/s11627-013-9589-6

Kumar V., M. M. Naidu and G. Ravishankar (2006) Developments in coffee biotechnology in vitro plant propagation and crop improvement. Plant Cell, Tissue and Organ Culture 87:49-65, https://doi.org/10.1007/s11240-006-9134-y

Kumar K. and I. Rao (2012) Morphophysiological problems in acclimatization of micropropagated plants in ex vitro conditions- a review. Journal of Ornamental and Horticultural Plants 2: 271-283.

Li C., Y. Li, Y. Shi, Y. Song, D. Zhang, E. S. Buckler ... and Y. Li (2015) Genetic control of the leaf angle and leaf orientation value as revealed by ultra-high density maps in three connected maize populations. PLOS ONE 10:e0121624, https://doi.org/10.1371/journal.pone.0121624

López-García F. J., E. Escamilla-Prado, A. Zamarripa-Colmenero y J. G. CruzCastillo (2016) Producción y calidad en variedades de café(Coffea arabica L.) en Veracruz, México. Revista Fitotecnia Mexicana 39:297-304, https://doi.org/10.35196/rfm.2016.3.297-304

López-Gómez P., L. Iracheta-Donjuan, M. Castellanos-Juárez, I. Méndez-López, A. Sandoval-Esquivez, J. F. Aguirre-Medina, ... y A. Gutierrez-Díez (2010) Influencia del explante y medio de cultivo en la embriogénesis somática en hojas de café. Revista Fitotecnia Mexicana 33:205213, https://doi.org/10.35196/rfm.2010.3.205

Maciel A. L. R., F. A. Rodrigues, M. Pascual and C. H. S. de Carvalho (2016) Acclimatization of coffee (Coffea racemosa x Coffea arabica) somaclones obtained from temporary immersion bioreactor system $\left(\mathrm{RITA}^{\circledR}\right)$. Australian Journal of Crop Science 10:169-175.

Márquez-Martín B., R. Sesmero, M. A. Quesada, F. Pliego-Alfaro and C. SánchezRomero (2011) Water relations in culture media influence maturation of avocado somatic embryos. Journal of Plant Physiology 168:2028-2034, https://doi.org/10.1016/j.jplph.2011.06.008

Martínez M. T., A. M. Vieitez and E. Corredoira (2015) Improved secondary embryo production in Quercus alba and Q. rubra by activated charcoal, silver thiosulphate and sucrose: influence of embryogenic explant used for subculture. Plant Cell, Tissue and
Organ Culture 121:531-546, https://doi.org/10.1007/s11240015-0722-6

Martínez S. D. J., R. Gómez-Kosky, R. Barbón, R. Collado, M. Pérez, N. Veitia y M. Rodríguez (2017) Maduración y germinación de embriones somáticos de Sorghum bicolor (L.) Moench cultivar 'CIAP 132R-05'. Biotecnología Vegetal 17:3339.

Montalbán I., N. De Diego and P. Moncaleán (2010) Bottlenecks in Pinus radiata somatic embryogenesis: improving maturation and germination Trees 24:1061-1071, https://doi.org/10.1007/s00468-010-0477-y

Montes-Cruz S., J. M. Lalama-Aguirre, J. Echeverria-Felix, L. ToromorenoArevalo, S. Salazar-Torres, E. Benavides-Burgos y J. Atiaja-Llamba (2017) Obtención de embriones somáticos de cafeto a partir de explantes de hojas de las variedades Bourbón Cidra, Caturra Rojo y SL-28 de plantaciones establecidas en la provincia del Carchi, Zona 1, Ecuador. Dominio de las Ciencias 3:918-942.

Murashige T. and F. Skoog (1962) A revised medium for rapid growth and bio assays with tobacco tissue cultures. Physiologia Plantarum 15:473-497, https://doi.org/10.1111/j.1399-3054.1962.tb08052.x

Pereira A. R., S. P. Carvalho, M. Pasqual e F. C. Santos (2007) Embriogênese somática direta em explantes foliares de Coffea arabica L. cv. Acaiá Cerrado: efeito de cinetina e ácido giberélico. Ciência e Agrotecnologia 31:332-336 https://doi.org/10.1590/S1413-70542007000200010

Ptak A., A. El Tahchy, E. Skrzypek, T. Wójtowicz and D. Laurain-Mattar (2013) Influence of auxins on somatic embryogenesis and alkaloid accumulation in Leucojum aestivum callus. Central European Journal of Biology 8:591-599, https://doi.org/10.2478/s11535-013-0160-y

Quiroz-Figueroa F., C. Fuentes-Cerda, R. Rojas-Herrera and V. Loyola-Vargas (2002) Histological studies on the developmental stages and differentiation of two different somatic embryogenesis systems of Coffea arabica. Plant Cell Reports 20:1141-1149, https://doi.org/10.1007/s00299-002-0464-x

Rai M. K., N. Akhtar and V. Jaiswal (2007) Somatic embryogenesis and plant regeneration in Psidium guajava L. CV Banarasi local. Scientia Horticulturae 113:129-133, https://doi.org/10.1016/j.scienta.2007.02.010

Renard H. M. C. y R. M. Larroa T. (2017) Política pública y sustentabilidad de los territorios cafetaleros en tiempos de roya: Chiapas y Veracruz. Estudios Latinoamericanos 40:95113, https://doi.org/10.22201/cela.24484946e.2017.40.61593

Reyes-DíazJ.I.,A.M. Arzate-Fernández,J.L.Piña-EscutiaandL.M. Vázquez-García (2017) Media culture factors affecting somatic embryogenesis in Agave angustifolia Haw. Industrial Crops and Products 108:81-85, https://doi.org/10.1016/j.indcrop.2017.06.021

Rezende J. C., C. H. S. Carvalho, M. Pascual, A. C. R. Santos e S. M. Carvalho (2011) Calli induction in leaf explants of coffee elite genotypes. Ciência Rural 41:384-389, https://doi.org/10.1590/S0103-84782011000300004

Rudiyanto S. P., D. Efendi and T. M. Ermayanti (2014) Somatic embryo germination of Jatropha curcas $L$. in presence of sucrose and poly ethylene glycol (PEG). Annales Bogorienses 18:35-43.

SAGARPA, Secretaría de Agricultura, Ganadería, Desarrollo Rural, Pesca y Alimentación (2017) Planeación Agrícola Nacional 2017-2030. Secretaría de Agricultura, Ganadería, Desarrollo Rural, Pesca y Alimentación. Ciudad de México. 33 p

Santana-Buzzy N., R. Rojas-Herrera, R. M. Galaz-Ávalos, J. R. Ku-Cauich, J. Mijangos-Cortés, L. C. Gutiérrez-Pacheco, ... and V. M. Loyola-Vargas (2007). Advances in coffee tissue culture and its practical applications. In Vitro Cellular and Developmental Biology - Plant 43:507-520, https://doi.org/10.1007/s11627-007-9074-1

SAS Institute (2002) SAS/STAT User's Guide. Version 8. Sixth edition. SAS Institute. Cary, North Carolina, USA. 112 p.

Sghaier-Hammami B., J. V Jorrín-Novo, R. Gargourl-Bouzid and N. Drira (2010) Abscisic acid and sucrose increase the protein content in date palm somatic embryos, causing changes in 2-DE profile. Phytochemistry 71:1223-1236, https://doi.org/10.1016/j.phytochem.2010.05.005

Shewry P. R. and N. G. Halford (2002) Cereal seed storage proteins: structures, properties and role in grain utilization. Journal of Experimental Botany 53:947-958, https://doi.org/10.1093/jexbot/53.370.947

SIAP, Servicio de Información Agroalimentaria y Pesquera (2020) Anuario estadístico de laproducción agrícola. Secretaría de Agricultura y Desarrollo Rural. Ciudad de México. https://nube.siap.gob. $\mathrm{mx} /$ cierreagricola/ (Mayo 2021)

Singh R., M. K. Rai and N. Kumari (2015) Somatic embryogenesis 
and plant regeneration in Sapindus mukorossi Gaertn. from leaf-derived callus induced with 6-benzylaminopurine. Applied Biochemistry and Biotechnology 177:498-510, https://doi.org/10.1007/s12010-015-1758-0

Sivanesan I., M. S. Son, S. Jana and B. R. Jeong (2012) Secondary somatic embryogenesis in Crocus vernus (L.) Hill. Propagation of Ornamental Plants 2:163-170.

Stasolla C., L. van Zyl, U. Egertsdotter, D. Craig, W. Liu and R. R. Sederoff (2003) The effects of polyethylene glycol on gene expression of developing white spruce somatic embryos. Plant Physiology 131:49-60, https://doi.org/10.1104/pp.015214

Steiner A. A. (1984) The universal nutrient solution. In: Proceedings of the 6th International Congress on Soilless Culture. International Society for Soilless Culture. Wageningen, The Netherlands. pp:633-649.

Tikkinen M., S. Varis and T. Aronen (2018) Development of somatic embryo maturation and growing techniques of Norway spruce emblings towards large-scale field testing. Forests 9:325, https://doi.org/10.3390/f9060325

Unigarro-Muñoz C. A., J. D. Hernández-Arredondo, E. C. Montoya-Restrepo, R. D. Medina-Rivera, L. N. Ibarra-Ruales, C. Y. Carmona-González and C. P. Flórez-Ramos (2015) Estimation of leaf area in coffee leaves (Coffea arabica L.) of the Castillo variety. Bragantia 74:412-416, https://doi.org/10.1590/1678-4499.0026

USDA, United States Department of Agriculture (2018) Mexico. Coffe annual. Coffee plan on track to achieve goals. GAIN Report Number: MX8023. USDA Foreign Agriculture Service. Washington, D. C. USA. 10 p. https://apps.fas.usda.gov/newgainapi/api/report/ downloadreportbyfilename?filename=Coffee\%20Annual Mexico\%20City_Mexico_5-15-2018.pdf (Mayo 2021).

Vahdati K., S. Bayat, H. Ebrahimzadeh, M. Jariteh and M. Mirmasoumi (2008) Effect of exogenous $\mathrm{ABA}$ on somatic embryo maturation and germination in Persian walnut (Juglans regia L.). Plant Cell, Tissue and Organ Culture 93:163-171, https://doi.org/10.1007/s11240-008-9355-3

Vale E. D. M., A. S. Heringer, T. Barroso, A. T. D. Ferreira, M. N. da Costa, J. E. A. Perales, ... and V. Silveira (2014) Comparative proteomic analysis of somatic embryo maturation in Carica papaya L. Proteome Science 12:37, https://doi.org/10.1186/1477-5956-12-37

Vanegas E. P. E., I. Benítez-García, A. L. Leyva P., O. Paredes-López and A. A. Del Villar-Martínez (2017) Somatic embryogenesis from leaf explants of Tagetes erecta L. Plant Biotechnology 34:187-192, https://doi.org/10.5511/plantbiotechnology.17.1120a

Yasuda T., Y. Fujii and T. Yamaguchi (1985) Embryogenic callus induction from Coffea arabica leaf explants by benzyladenine. Plant Cell Physiology 26:595-597, https://doi.org/10.1093/oxfordjournals.pcp.a076946 
